34. Pelech SL. Pritchard PH, Brindley DN, Vance DE 1983 Fatty acids promote translocation of CTP:phosphocholine cytidylyltransferase to the endoplasmic reticulum and stimulate rat hepatic phosphatidylcholine synthesis. J Biol Chem 258:6782-6788

35. Gilfillan AM, Smart DA, Rooney SA 1985 Phosphatidylglycerol stimulates cholinephosphate cytidylyltransferase activity and phosphatidylcholine synthesis in type II pneumocytes. Biochim Biophys Acta 835:141-146

36. Chu AJ. Rooney SA 1985 Stimulation of cholinephosphate cytidylyltransferase activity by estrogen in fetal rabbit lung is mediated by phospholipids. Biochim Biophys Acta 834:346-356

37. Hallman M. Gluck L 1980 Formation of acidic phospholipids in rabbit lung during perinatal development. Pediatr Res 14:1250-1259

38. Rosenberg IL. Smart DA. Gilfillan AM, Rooney SA 1987 Effect of 1-oleoyl-2acetylglycerol and other lipids on phosphatidylcholine synthesis and cholinephosphate cytidylyltransferase activity in cultured type II pneumocytes. Biochim Biophys Acta 921:473-480

\title{
Announcement
}

\section{Nominations for the 1994 E. Mead Johnson Award for Research in Pediatrics}

Nominations are invited for the 1994 E. Mead Johnson Award for Research in Pediatrics. Each of two recipients will receive an honorarium of $\$ 10,000$ plus travel expenses to attend the 1994 meeting of the Society for Pediatric Research in Seattle, WA, where recipients will present their research at a special seminar.

Eligibility for the 1994 award:

1) Nominees must have received their doctoral degree in 1974 or later

2) Limited to investigators in the Americas

3) Research is related to pediatrics and recently published, perhaps coming to fruition or attaining recognition during the past few years

Candidates are nominated by their Department Chairs or past E. Mead Johnson Award recipients. The deadline for submission is December 3, 1993. Nomination forms may be obtained from: Debbie L. Anagnostelis. The Society for Pediatric Research. P.O. Box 675, Elk Grove Village, IL 60009-0675. 